\title{
LESSON 144
}

Tabulation 40

PAPER: Suitable.

TARGET TIME: 20 minutes.

Rule up.

Letter 49

TARGET TIME: 28 minutes.

Type a correct copy of this circular letter. Leave room for the insertion of the inside address. Type the display section in double-line spacing and put in leader dots.

\begin{tabular}{|c|c|c|c|c|c|}
\hline \multicolumn{2}{|c|}{ Contributions } & \multicolumn{3}{|c|}{ Value at end of: } & \multirow{2}{*}{$\begin{array}{l}\text { Life } \\
\text { Aosurance } \\
\text { Protection }\end{array}$} \\
\hline $\begin{array}{l}\text { monthly } \\
\text { Outlay }\end{array}$ & $\begin{array}{l}\text { outlay } \\
\text { aftes tax } \\
\text { relief }\end{array}$ & $\begin{array}{l}3 \\
\text { yeas }\end{array}$ & $\sum_{\text {year }}^{5}$ & $\begin{array}{l}10 \\
\text { yean }\end{array}$ & \\
\hline $\begin{array}{c}6 \\
1 \\
12 \\
24 \\
36 \\
48\end{array}$ & $\begin{array}{c}7 \\
5.08 \\
10.16 \\
20.32 \\
30.48 \\
40.64\end{array}$ & $\begin{array}{l}f \\
196 \\
388 \\
777 \\
864 \\
1,352\end{array}$ & $\begin{array}{c}f \\
348 \\
696 \\
1,397 \\
2,088 \\
2,686\end{array}$ & $\begin{array}{l}f \\
836 \\
1.672 \\
3.346 \\
4.016 \\
6.686\end{array}$ & $\begin{array}{c}f \\
1,025 \\
2,050 \\
4,100 \\
6,150 \\
8,200\end{array}$ \\
\hline & asso & & & & $\begin{array}{l}\text { uofed are } \\
\text { Amounts are }\end{array}$ \\
\hline
\end{tabular}

From: The Dorcheotor Building Socinty, IIA High Streat, DORCHESTER . DO3/AS To day's date. Dear Sir/ Mddam, INVESTMENT IMTEREST RATES In acceodance w. t. recmondta. oft. Bulding Sorietis A sesten, if sh. t. Sociaty is a mamber, $t$. Directors hure. decided to nduce t. atteo of intareat H. hee. Vean offered avert. lant 18 months binvestars. I1 hure. accordingly bea intructed by t. liventato to give $y$. notice th. t. rate of interest on yr. Inveatement. A/c $w$. t. Sricity we. be reduced by $\frac{1}{2} \%$ per annum from (acitable data) (From th. date t. rites

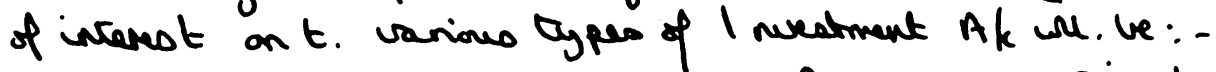

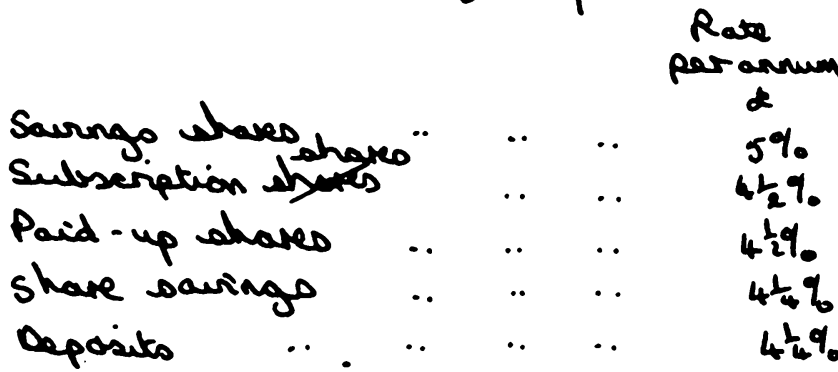

Equedent will Shindard Tax Rate

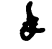

$9.02 \%$

$8.01 \%$

$8.01 \%$

$7.55 \%$ $7.55 \%$

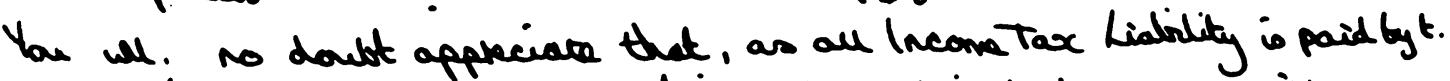

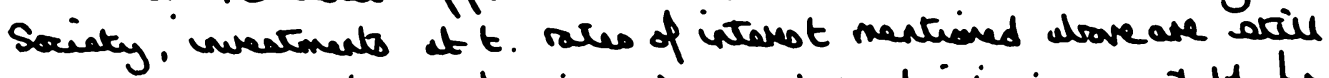

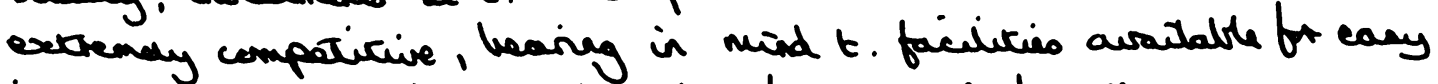

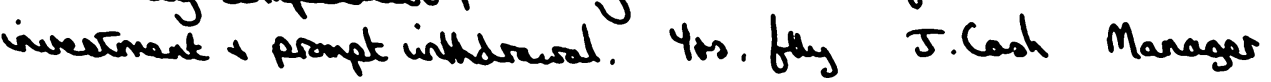

